\title{
Author Index Vol. 6, 1987
}

Neuroepidemiology 1987;6:239

\section{Author Index}

Alter, M. 85 Amery,W.K. 220 Andersen, A.R. 190 Araki,S. 120

Baron, J.C. 229 Bates, D. 6 Bois,E. 139 Bonaiti, C. 139

Bousser, M.G. 150,229

Camenga, D. 85 Clifford Rose, F. 5 Compston, A. 34 Confavreux, C. 101

Couch, J.R., Jr. 178

Debroye,M. 220 Diamond, S. 172 Dom,F. 220

Espir,M.L.E. 94

Feingold,J. 139 Feingold,N. 139 Freitag,F.G. 172

Greenstein, J. 85

Hedman, C. 190

Hockaday, J.M. 235 Hoing,M. 220

Josse,M.O. 150

Kalafatova, O. 116 Kasagi, S. 130 Kumamoto, T. 120 Kunkel.R.S. 209

Kurtzke,J.F. 17

Lallemant, M. 139 Laplane,D. 150 LaRue,L. 85 Lewis, J.A. 198

Mas,J.L. 150

Mayer, F.M. 139 McCarthy, M. 94 Mehta,N. 172 Mito,T. 130 Moatti.L. 139

Molgaard, C.A. 153

Nielsen, S.L. 214 
01esen,J. 190 Ootani, K. 130

Perkin, G.D. 40 Prusinski, A. 186

Robinson, I. 46

Shorvon,S.D. 94 Solomon, G.D. 172 Solomon, S. 164

Takeshita,K. 130 Tanaka,T. 130 Taylor, R.C. 77 Tfelt-Hansen, P. 214

Touboul.PJ. 150 